Revista Docência do Ensino

Superior

v. 1, 2011

\section{REFLEXÕES SOBRE A DIDÁTICA 2.0}

\author{
REFLECTIONS ON EDUCATION 2.0
}

\section{RESUMO}

O ensaio busca recuperar experiências acerca das novas tecnologias de informação e de comunicação e sua aplicação no universo educacional, especialmente no plano do e-learning e da educação a distância, enfrentando ainda os riscos de degeneração da sociedade do conhecimento em sociedade da ignorância.

Palavras-Chave: TICs. Educação a distância. Sociedade do conhecimento.

\section{ABSTRACT}

The essay aims to recover experiences about the new information and communication technologies and its application to the educational universe, especially in the plan of the e-learning, facing the risks of the degeneration of the knowledge society into a society of the ignorance.

Keywords: IT's. E-learning. Knowledge society. 


\section{INTRODUÇÃO}

Once I was a scuba diver in the sea of words. Now I zip along the surface like a guy on a Jet Ski. Nicholas Carr ${ }^{1}$

Os tempos recentes - esses tempos chamados de Contemporaneidade e marcados, simbolicamente, pela construção do projeto civilizatório que denominamos Estado de Direito - correspondem a três grandes revoluções na vida social e econômica: o vapor, conexo à Revolução Industrial e ao Estado liberal de Direito; a eletricidade, já alimentadora do Estado social; e a telemática, cá no nosso tempo de vida. ${ }^{2}$

A comunicação a distância (ou telemática), que nos torna próximos em um espaço virtual, tem fôlego para transformar muitíssimo a vida, nos próximos tempos, como já o vem fazendo. Quase a terceira parte da população mundial já é internauta.

Enquanto a revolução digital avança, há vozes que se questionam acerca dos efeitos da rede e da sua incidência sobre o cérebro humano. Parece que a nossa capacidade de concentração diminui e nos entregamos dia a dia às multitarefas digitais (navegando, chateando, via facebook, no youtube...), todas ao mesmo tempo, em muitas janelas simultaneamente abertas.

A internet oferece tantas possibilidades que parece que, para poder aproveitálas todas, nos vemos impelidos a procurar informação breve e concisa, afastando-nos da concentração que requer aprofundar-se num só tema.

Apesar de o uso que se faz da rede ser evidentemente uma opção pessoal, a tecnologia parece nos impelir para um determinado tipo de atuação. Confrontados à possibilidade de dispor de tantos livros, museus, obras de arte, cinema, há quem escolha a fórmula de pequenas sinopses informativas, não se aprofundando muito em nada, para conseguir um amplo espectro de "conhecimentos". Isto faz com que mude, na vida real e quotidiana, a maneira de perceber e priorizar os valores e o nosso meio,

1 CARR, Nicholas. Is Google Making Us Stupid? The Atlantic, July-August 2008. Disponível em: http://www.theatlantic.com/magazine/archive/2008/07/is-google-making-us-stupid/6868/. Acesso em: julho de 2011. Nicholas Carr é um jornalista renomado, e em sua homepage encontramos interessantes textos sobre os novos tempos; $c f$. http://www.nicholasgcarr.com/.

2 Miguel Reale trabalha os três momentos em seu REALE, Miguel. Nova Fase do Direito Moderno. 2. ed. São Paulo: Saraiva, 1998, inspirando a articulação das três mutações econômicas com os momentos do Estado de Direito (liberal, social e democrático) albergada em HORTA, José Luiz Borges. História do Estado de Direito. São Paulo: Alameda: 2011. 
bem como a nossa capacidade de raciocínio e de gestão das emoções, o que pode nos desumanizar, se nos deixarmos engolir pelo seu ritmo frenético.

\section{QUE SÃO AS TIC'S?}

As tecnologias de informação e de comunicação (TIC's, ou NTIC para novas tecnologias de informação e de comunicação, ou ainda IT para "Information Technologies") agrupam os elementos e as técnicas utilizadas no tratamento e na transmissão das informações, principalmente os informáticos, relativos à internet e às telecomunicações em geral.

Kofi Annan, secretário-geral da Organização das Nações Unidas (ONU), reconheceu já em 2003:

As tecnologias de informação não são fórmula mágica ou panacéia, mas são uma força poderosa que pode e deve ser atrelada à nossa missão global de paz e desenvolvimento. ${ }^{3}$

As TICs podem ser consideradas um conceito dinâmico ${ }^{4}$. Desde a invenção da escrita, descobertas como o telégrafo, o telefone, a televisão, o computador, a internet, a telefonia móvel, o GPS têm-nos conduzido a uma cada vez mais evidente sociedade da informaçãa $0^{5}$.

Os usos das TICs não param de crescer e de se estender, sobretudo nos países ricos, com o risco de acentuar localmente a fratura digital e social e as diferenças entre gerações e gêneros. Desde a agricultura de precisão e a gestão das reservas florestais à

\footnotetext{
${ }^{3}$ No original: "Information technology is not a magic formula or panacea. But it is a powerful force that can and must be harnessed to our global mission of peace and development." [apud CARPENTER, Mark. Older Wiser Wired: Working to Bridge the Digital Divide. Disponível em: http://www.aarpinternational.org/resourcelibrary/resourcelibrary_show.htm?doc_id=547051, acessado em setembro de 2011]. Naquele ano, reunir-se-ia a World Summit on the Information Society (WSIS) (ou Cúpula Mundial sobre a Sociedade da Informação), em duas fases, a primeira em Genebra, em 2003, e a segunda em Tunis, em 2005. O tema das TICs, incluindo comentários a Kofi Annan, aparece nas reflexões de Abdul Paliwala: PALIWALA, Abdul. Legal Regulation and uneven Global Digital Diffusion. Disponível em: http://www.bakercyberlawcentre.org/2004/talks/LTT_paliwala_digivide3.rtf. Acesso em: julho de 2011; PALIWALA, Abdul. Free Culture, Global Commons and Social Justice in Information Technology Diffusion. Journal of Information, Law \& Technology (JILT), Coventry, University of Warwick, 2006. Disponível em: http://www2.warwick.ac.uk/fac/soc/law/elj/jilt/2006_1/paliwala. Acesso em: setembro de 2011.

${ }^{4}$ MARKUS, M. Lynne; ROBEY, Daniel. Information Technology and Organizational Change: causal structure in theory and research. Management Science, v. 34, n. 5, may 1988, p. 583-598.

5 A ideia de uma sociedade da informação está em desenvolvimento, sob diversos conceitos e por diversos pensadores, desde os anos 1960. Refere-se substancialmente à modificação nos marcos do próprio sistema capitalista, que passa a reconhecer no conhecimento um capital de grande relevo. Em marcos pósindustriais, o capitalismo evolui para um capitalismo informático, ou em rede, numa sociedade também em rede. O teórico mais influente no tema, hoje, é Manuel Castells, que publicou a importante trilogia La
} 
monitoração global do meio ambiente planetário ou da biodiversidade (TICs ao serviço do desenvolvimento sustentável), da democracia participativa passando pelo comércio, a telemedicina, a informação, a gestão de múltiplas bases de dados, a bolsa de valores, a robótica e os usos militares, a ajuda e apoio para os portadores de necessidades especiais, as TICs tendem a ocupar grande parte do desenvolvimento humano, com uma consequente perda de liberdade individual. (Bons exemplos desta perda de liberdade são o efeito Grande Irmão e a invasão crescente da publicidade dirigida e indesejada.) Os prospectivistas ${ }^{6}$ pensam que as TICs terão um lugar crescente e poderiam ser a origem de um novo paradigma de civilização.

\section{SOCIEDADE DA INFORMAÇÃO OU SOCIEDADE DA IGNORÂNCIA?}

Hoje, a ninguém surpreende estar informado minuto a minuto, comunicar-se com gente da outra ponta do planeta, ver o vídeo de uma canção ou trabalhar em equipe sem estar em um mesmo lugar. Com uma rapidez impensada, as Tecnologias de Informação e Comunicação são cada vez mais parte importante das nossas vidas. Esta perspectiva da Sociedade da Informação, devemos principalmente a um invento que começou a cristalizar-se há quatro décadas: a Internet. O seu desenvolvimento fez com que a informação agora reste em muitos lugares e não tão somente nas mãos dos pais e mestres e nos livros, onde se concentrava.

Daí decorre um novo problema: a confiabilidade e a qualidade desse excesso de informação. Se bem se permite a interconexão e a interatividade instantâneas com elevados parâmetros de imagem e som, e ao mesmo tempo favorecendo o aparecimento de novos códigos e linguagens e a especialização progressiva dos conteúdos (rompendo, de certa forma, a cultura de massas) e dando lugar à realização de atividades inimagináveis em pouco tempo, também supõem-se o isolamento e a desconexão social e física que acabam por facilitar a indução e o direcionamento para um pensamento único. ${ }^{7}$

Era de la Información; cf. CASTELLS, Manuel. La Era de la Información. V. I: La Sociedad Red; V. II: El poder de la identidad. V. III: Fin de Milenio. México, Distrito Federal: Siglo XXI Editores. 2001-2.

6 A Prospectiva, ou os Future Studies, é a disciplina que busca antecipar o futuro para compreendê-lo e nele poder influir. A prospecção de cenários futuros é capítulo essencial de quaisquer estudos estratégicos, possuindo grande prestígio nas academias militares e think tanks de ponta.

${ }^{7}$ Para uma compreensão da real dimensão do avanço do pensamento único no tempo presente, v. MAYOS, Gonçal. Genealogia i crítica del pensament únic. In: AAVV. Globalització; Pensament únic. Barcelona: Liceu Joan Maragall, La Busca Edicions, 2000, p. 17-40. 
Gérard Ayache, em A grande confusão, ${ }^{8}$ fala de hiperinformação para sublinhar o impacto antropológico das novas tecnologias. Numerosos internautas consideram a Internet uma tecnologia de relação.

Gonçal Mayos, na obra coletiva A Sociedade da Ignorância,${ }^{9}$ indaga se a sociedade do conhecimento possui uma face oculta: Que perigos podem se esconder por trás das suas maravilhosas promessas? Quantos custos e "danos colaterais" a acompanham? Tudo é conhecimento, e tão só conhecimento? Que matizes e limites lhe são constitutivos e que faz falta ter em conta? Escapa ao nosso controle? Como pode o conjunto da população "empoderar-se" da sociedade do conhecimento? Falhar neste "empoderamento" não é cair na sociedade da ignorância, da incultura e da incivilidade?

Na obra organizada por Mayos, importantes pensadores debruçam-se sobre os dilemas da sociedade da ignorância: Antoni Brey reflete sobre a relação do indivíduo com o conhecimento no mundo hiperconectado, e Marina Subirats sobre a sociedade do conhecimento e as dificuldades da sua produção; a "crise de sentido" é destacada por Joan Campàs juntamente com o denominado softpower, perguntando-se o que é informação? Toda a informação é conhecimento? Quem decide o que é e o que não é conhecimento? Qual é o encaixe na sociedade atual das novas tecnologias? E não menos importante: como se pode combater a cultura amnésica? Ferran Ruiz não se esquece das dificuldades e desafios que apresentam o educar, entre a evasão e a utopia, advogando uma nova utopia que supere a despersonalização da atual indústria da educação. Daniel Innerarity mergulha, enfim, na sociedade do desconhecimento.

\section{DO E-LEARNING À "PEDAGOGIA INFORMACIONAL"}

A formação é um elemento essencial ao processo de incorporar as novas tecnologias às atividades quotidianas. O e-learning é o tipo de ensino que se caracteriza pela separação física entre o professor e o aluno, e que usa a internet como canal de distribuição do conhecimento e como meio de comunicação.

É de destacar-se o problema da pouca capacidade que tem a escola, em geral, para absorver as novas tecnologias. Neste sentido, surge o conceito de NTAE (Novas Tecnologias Aplicadas à Educação). Entre os benefícios mais claros que os meios de comunicação podem trazer à sociedade se encontram o mais amplo e universal acesso

${ }^{8}$ V. http://www.lagrandeconfusion.com/, acessado em julo de 2011.

${ }^{9}$ MAYOS, Gonçal; BREY, Antoni (orgs). La Sociedad de la Ignorancia. 2. ed. Barcelona: Península, 2011. 
à cultura e à educação, onde os avanços tecnológicos e os benefícios que comporta a era da comunicação em que vivemos lançam um balanço e umas previsões extraordinariamente positivas. A educação tem de reindagar-se sobre os seus objetivos, metas, pedagogias e didáticas. As mesmas forças que fazem tão necessária a aprendizagem a querem agradável e prática: as escolas estão se reinventando ao redor da tecnologia da informação. As redes educativas virtuais estão se transformando nas novas unidades básicas do sistema educacional, que incluem o desenho e a construção de novos cenários educativos, a elaboração de instrumentos eletrônicos de ensino e a formação de educadores especializados na docência num novo espaço social.

A mundialização das TICs, permitindo um acesso vinte e quatro horas, de qualquer ponto do globo, a um amplo conjunto de recursos, vai acompanhada de efeitos perversos em termos de segurança e de ética, agravados pela internacionalização de determinadas atuações.

As novas tecnologias influem notoriamente nos processos de criação e mudança das correntes de opinião pública. ${ }^{10}$ Objetos tão habituais como a televisão, o telefone móvel celular e o computador, além do rádio, estão constantemente transmitindo mensagens, tentando trazer ao seu terreno os ouvintes, telespectadores ou usuários desses meios. Através de mensagens de texto, correios eletrônicos, blogs e outros espaços na internet, as pessoas deixam-se influir quase sem serem conscientes disto, crendo em versões dos fatos porque o disseram a mídia ou a net; estas são a via da verdade para muitos dos cidadãos, sem saber que neles também se mente e manipula e desconhecendo a confusão entre o canal de comunicação ou emissor da informação e aquele que gerou a mensagem (com frequência escondido ou não bastante explícito). Dependendo da idade, status social, nível de educação e estudos, bem como da vida, trabalho e costumes, as TICs têm um maior ou menor impacto, positivo ou devastador em termos culturais.

Oscar Picardo propõe a construção de uma pedagogia informacional, ${ }^{11}$ tentando ensinar a aprender na sociedade do conhecimento. Reconhece a necessidade de construir-se uma educação telemática (ou a distância, por internet), de modo tão rigo-

\footnotetext{
${ }^{10}$ Sobre os impactos (negativos) da imagem sobre os saberes e a cultura, bem como sobre o nefasto caminho de uma videocracia, v. SARTORI, Giovanni. Homo Videns: televisão e pós-pensamento. Trad. Simonetta Neto. Lisboa: Terramar, 2000.

${ }^{11}$ Cf. PICARDO JOAO, Oscar Carlos. Pedagogía Informacional: Enseñar a aprender en la sociedad del conocimiento. Edutec, Revista Electrónica de Tecnología Educativa, Palma de Mallorca, Universitat de les Illes Balears, n. 15, mayo 2002. (Interessante anotar o interesse da UIB em educação a distância. Sediada na Ilha de Mallorca, a UIB mantém pólos de EAD nas ilhas de Menorca e Ibiza, onde oferece parte das disciplinas
} 
roso quanto a educação presencial. O processo avaliativo, normalmente a partir dos fóruns de debates virtuais, exige do educando tempo suficiente às leituras do curso e para participar em um processo dialógico, construtivo e que maximize os meios.

Reconhece que a efetividade pedagógica das novas tecnologias pede a desmitificação de ao menos três aspectos: que o computador vá poupar trabalho; que o computador vá substituir o professor, e que a internet e a cultura digital farão desaparecer os livros. Ao contrário, elaborar materiais didáticos em multimídia dá muito trabalho, a carinhosa presença humana é insubstituível, e os livros continuarão sendo e precisam ser sublinhados, distribuídos e apalpados.

Com inteligência, refere-se à festejada noção de que saber é poder, lembrando passagem em O Pêndulo de Foucault na qual Umberto Eco reflete: "não há informações melhores do que as outras, a vantagem está em se ficharem todas e depois procurar as conexões. As conexões existem sempre, basta querer encontrá-las". ${ }^{12}$ Fica transparente, portanto, o imenso desafio correlato ao e-learning, um desafio que exige - considerando as economias informacionais e a cultura da informação - o desenvolvimento de novas habilidades informacionais (à moda de Literacy skills) justapostas e análogas às emergentes manifestações dos analfabetismos funcionais (informático, idiomático e de informações). Registra que tais cenários pedem uma nova arquitetura educativa que aponte e aposte na aprendizagem por toda a vida (lifelong learning), o que nos leva ao interessante tema do direito à educação continuada, aliás, proposto por Roberto Mangabeira Unger e por nós abraçado, ${ }^{13}$ segundo o qual o trabalhador, economicamente ativo, necessita de permanente acesso à atualização de seus saberes, o que evidentemente não se poderia oferecer no ambiente da escola tradicional e, ao contrário, pode ser muitíssimo potencializado no ambiente da escola virtual.

Na pedagogia informacional de Picardo, os docentes e discentes têm de assumir um novo papel de mediações entre a experiência humana e a informação existente, tomando a informação como ponto de partida e de chegada no processo de ensino e aprendizagem, especialmente em um universo no qual ganham relevo, para o sistema

integrantes de diversos cursos. Como a comunicação entre as ilhas é bastante deficiente, a internet tem ajudado em sua expansão e na socialização de saber).

${ }^{12}$ ECO, Umberto. O Pêndulo de Foucault. Trad. Ivo Barroso. Rio de Janeiro: Record, 1989, p. 215. Essa ideia, a de que o verdadeiro saber está em conectar saberes, subjaz na concepção de doutor que nos anima: um doutor é capaz de fazer conexões originais.

${ }^{13}$ Cf. UNGER, Roberto Mangabeira. O que a Esquerda deve propor. Trad. Antonio Risério Leite Filho. Rio de Janeiro: Civilização Brasileira, 2008, p. 101; HORTA, José Luiz Borges. Perfil e Dilemas do Direito à Educação. Revista da Faculdade de Direito, Belo Horizonte, Universidade Federal de Minas Gerais [no prelo]. 
econômico (capitalista) da cultura do microchip, da informação, da telemática e da robótica, a informação e o conhecimento como capital por excelência.

A pedagogia informacional, pela sua própria conceptualização, está intimamente relacionada às TICs, consonantes às substantivas ideias que orientam o futuro educativo das sociedades do conhecimento.

O e-learning nos pode oferecer, vale registrar, inúmeros benefícios que dizem respeito: à imersão prática num meio web 2.0, com suas imensas potencialidades; à eliminação de barreiras espaciais e temporais; à redução dos custos da educação, nos planos metodológico e logístico, também em decorrência de práticas em meios de simulação virtual; à gestão real do conhecimento, garantindo e estimulando intercâmbios de ideias, opiniões, práticas, experiências; ao enriquecimento coletivo do processo de aprendizagem, sem limites geográficos; à atualização constante dos conteúdos.

\section{PERSPECTIVAS DE UMA DIDÁTICA 2.0}

As Tecnologias de Informação e de Comunicação já são parte inafastável das nossas vidas, integrando a cultura tecnológica que nos rodeia e com a qual temos de conviver; elas ampliam nossas capacidades físicas e mentais, e bem assim nossas possibilidades de desenvolvimento social.

Em que pesem estas magníficas credenciais que fazem das TICs instrumentos altamente úteis para qualquer um, e por certo imprescindíveis para toda empresa, há várias circunstâncias que dificultam uma sua mais ampla difusão entre todas as atividades e cepas sociais: problemas técnicos, de segurança, econômicos e culturais. Ao mesmo tempo, seu provável desenvolvimento pode se caracterizar por um progressivo aumento dos sistemas informáticos portáteis, pela implantação das telas planas e das tecnologias wi-fi, consolidação da universalização do acesso à telefonia móvel celular, multiplicação das atividades desenvolvidas no ciberespaço, e sem dúvida a generalização do uso das lousas digitais mesmo nas aulas presenciais.

Tudo isto representa desafios à sociedade da informação, bem como a todos nós, que teremos de nos capacitar para poder acompanhar a mudança contínua, a rápida caducidade da informação e a necessidade de uma formação permanente para se adaptar às novas exigências da vida profissional e para reestruturar o conhecimento pessoal. A gestão da interminável informação disponível e a necessidade de organizar um sistema pessoal de fontes informativas e dispor de técnicas e critérios de busca e 
seleção de dados aparecem como desafios correlatos, bem como garantir a presença produtiva de cada um no ciberespaço. Há uma premente necessidade de verificar a veracidade e atualidade da informação, de se manter atualizado aos novos códigos comunicativos, para emitir, receber e interpretar mensagens nos novos meios.

É possível aproveitar os novos meios para resolver alguns dos problemas de difícil solução como a evasão escolar, o acesso à cultura, a sustentabilidade, a exclusão social. Tudo isto sem perder de vista nossos ideais e valores, e inclusive, senão mesmo especialmente, a própria identidade.

Mais que isso, a renovação das práticas pedagógicas pela via da introdução da internet no processo educativo possui razoável acúmulo de experiências, que já nos permite uma rica reflexão.

Em Barcelona, por exemplo, dois filósofos inovaram substancialmente o ensino em suas áreas, pela construção de homepages de amplo espectro. A Península Ibérica possui duas grandes universidades a distância, a Universidad Nacional de Educación a Distancia (a UNED, sediada em Madrid) e a Universitat Oberta de Catalunya (a UOC, sediada em Barcelona) ${ }^{14}$. Na UOC, ainda hoje, atuam tanto Ramon Alcoberro como Gonçal Mayos, cada um com seu inspirador portal na internet, e em ambos a experiência na educação a distância os permite transformar substancialmente o ensino de Filosofia.

Alcoberro é pioneiro em debates de Tecnoética e também no uso da internet como espaço do filosofar, e possui vasta obra intelectual, em grande parte recolhida em seu impactante sítio www.alcoberro.info, no qual inclusive mantém um blog.

Por sugestão, aliás, de Alcoberro, Mayos lançou em meados da década de 2000 sua web www.ub.edu/histofilosofia/gmayos/0index.htm. A página de Mayos traz duas novidades em relação à página de Alcoberro: somente contém textos publicados em outras mídias (especialmente a via tradicional, em papel) e conta com espaços em nada menos que sete idiomas (catalão, castelhano, inglês, francês, alemão, português e italiano). A primeira novidade realça a importância da página: ali, encontramos todas as publicações de Mayos, disponíveis para download. Por outro lado, os idiomas da página vieram sendo ditados pelas próprias publicações. À medida que publicava em um novo

\footnotetext{
${ }^{14}$ A UNED é uma potência educacional; universidade pública fundada precursoramente em 1972, conta hoje com 180 mil alunos e um conjunto invejável de docentes. Há catedráticos de imensa produção como professores em dedicação exclusiva à UNED, que se estrutura segundo o modelo tradicional de universidade. A UOC, por sua vez, foi fundada pela Generalitat de Catalunya em 1994, já em um modelo mais gerencial de gestão, cresce rapidamente e representa uma das mais significativas inovações catalãs.
} 
idioma, abria um novo espaço na web. (A única exceção é a língua italiana, que domina mas em que não se fez publicar, cujo campo cresce pela via das traduções de textos originalmente publicados em outros idiomas, levadas a cabo por colaboradores estrangeiros). ${ }^{15}$

Ambas as plataformas virtuais se mantêm em permanente atualização e referência de estudos em seu campo didático, reforçando a importância do uso da internet como suporte mesmo à educação presencial (em Barcelona, muitas vezes vemos Mayos abrindo a internet em classe - há computador, datashow e acesso à internet nas salas de aulas, como deve ser - e utilizando com os alunos textos disponíveis em sua web).

Igualmente na UFMG, desde meados dos anos 2000, buscamos formas de introduzir dimensões criativas (por exemplo) no ensino do Direito - e, mais recentemente, de Ciências do Estado - , sempre como fruto da constatação da permanente crise de paradigmas, métodos e perspectivas do ensino jurídico. ${ }^{16}$

Com apoio da Escola de Belas Artes e do Colégio Técnico (Coltec), ${ }^{17}$ mantivemos por um par de anos o Projeto Imago Juris, que visava renovar marcos pedagógicos, partindo da constatação de que toda a ênfase do Ensino Jurídico até aqui é dada na palavra, na capacidade de organização de ideias verbalizadas em cadência retórica, e de que muitas vezes a presença de imagens visuais, por exemplo em mapas (históricos, políticos e geográficos), poderia clarear a aprendizagem, tanto de História do Direito e do pensamento jurídico quanto de Direito Comparado, com grande impacto em diversos outros campos do ensino jurídico. O projeto ainda não pôde atingir seus objetivos e deverá ser retomado em breve, de modo a contarmos com uma mapoteca didática virtual e com um banco de imagens, ambos como um forte estímulo à utilização de meios audiovisuais de aprendizagem, com a qual por certo teríamos um contexto de ensinoaprendizagem muito mais eficiente. ${ }^{18}$

\footnotetext{
${ }^{15}$ O espaço em língua portuguesa foi aberto a partir de seu MAYOS, Gonçal. G. W. F. Hegel: Vida, pensamento e obra. Trad. Catarina Mourão. Barcelona: Planeta De Agostini, 2008, e dinamizado em tempos recentes, como parte de nossa atividade conjunta e do intercâmbio entre a UFMG e a Universitat de Barcelona, do qual nasceu o Grupo Internacional de Pesquisa em Cultura, História e Estado, coordenado pelos professores doutores Gonçal Mayos (UB) e José Luiz Horta (UFMG), que aliás em breve colocará no ar sua webpage www.macrofilosofia.eu.

${ }^{16}$ Recolhemos duas décadas de diagnósticos e propostas de mudança do ensino jurídico em HORTA, José Luiz Borges. Ensaios de Educação Jurídica. Belo Horizonte: Pergamum [no prelo].

${ }^{17}$ Consubstanciado em profunda interlocução com o professor Cristiano Gurgel Bickel, que nos ensinou muitíssimo sobre as interconexões entre Direito e Arte.

${ }^{18}$ No âmbito deste projeto (cujo nome original era Imagem e Direito; textos e contextos jusfilosóficos), produziu-se um ensaio de grande importância para pensarmos o futuro do ensino jurídico: CARVALHO, Bruno Nogueira de. A Sinestesia e o Ensino Jurídico; Por um diálogo entre o Simbolismo e o PósPositivismo. In: HORTA, José Luiz Borges; RAMOS, Marcelo Maciel (Org.). História, Identidade, Futuro: orientações jusfilosóficas. Belo Horizonte: Pergamum [no prelo]. Aliás, Mônica Sette Lopes, no âmbito do Ins-
} 
Cresce a cada ano, também no âmbito do Direito, a participação na educação a distância, mediada pela Universidade Aberta do Brasil (UAB), com a qual a Profa. Dra. Mariá Brochado possui um importante trabalho em desenvolvimento, no âmbito de seu Programa Paideia Jurídica, responsável pela oferta de formação em direitos humanos para professores de ensino fundamental e médio de vários polos do estado de Minas Gerais.

Mais recentemente, a Faculdade de Direito propôs à Pró-Reitoria de Graduação da UFMG o projeto Horizontes de Direito e Legislação, um esforço para aggiornamento, do ponto de vista de conteúdos e de métodos, da disciplina Direito e Legislação, integrante de cursos da Escola de Engenharia, que será transformada em disciplina ofertada na modalidade de educação a distância. ${ }^{19}$ E não pararemos por aí!

Transcender os limites da sala de aula tradicional tem infinitas vantagens. No plano da educação a distância, os recursos mencionados nos permitem uma melhor conciliação da vida familiar e trabalhista com uma mais ampla formação continuada, estimulando o nosso constante desenvolvimento humano, pessoal e social. Mais: promovem um perfil inovador de aluno: o que assume a tarefa de sua formação de modo proativo.

Trata-se de um desafio, no entanto, o de estabelecer uma Didática 2.0, apta a atender às grandes tarefas que se colocam à Universidade Pública e ao Estado, no século XXI.

\section{REFERÊNCIAS}

CARPENTER, Mark. Older Wiser Wired: Working to Bridge the Digital Divide. Disponível em: <http://www.aarpinternational.org/resourcelibrary/resourcelibrary_show.htm?doc_ id=547051 $>$. Acesso em: setembro de 2011.

CARR, Nicholas. Is Google Making Us Stupid? The Atlantic, July-August 2008. Disponível em: <http://www.theatlantic.com/magazine/archive/2008/07/is-googlemaking-us-stupid/6868/>. Acesso em: julho de 2011.

CASTELLS, Manuel. La Era de la Información. V. I: La Sociedad Red; V. II: El poder de la identidad. V. III: Fin de Milenio. México, Distrito Federal: Siglo XXI Editores. 2001-2.

ECO, Umberto. O Pêndulo de Foucault. Trad. Ivo Barroso. Rio de Janeiro: Record, 1989.

tituto de Estudos Avançados Transdisciplinares (IEAT) da UFMG, produziu o inspirado LACERDA, Bruno Amaro; LOPES, Mônica Sette. Imagens da Justiça. São Paulo: LTr, 2010.

${ }^{19}$ O projeto conta com equipe integrada pelos professores doutores José Luiz Horta, Karine Salgado, Daniela Muradas, Mariá Brochado e por bolsistas egressos dos cursos de bacharelado em Direito, Ciências Sociais e Engenharia Mecânica. 
HORTA, José Luiz Borges. Ensaios de Educação Jurídica. Belo Horizonte: Pergamum [no prelo].

HORTA, José Luiz Borges. História do Estado de Direito. São Paulo: Alameda, 2011.

HORTA, José Luiz Borges. Perfil e dilemas do direito à educação. Revista da Faculdade de Direito, Belo Horizonte, Universidade Federal de Minas Gerais [no prelo].

HORTA, José Luiz Borges; RAMOS, Marcelo Maciel (Org..) História, Identidade, Futuro: orientações jusfilosóficas. Belo Horizonte: Pergamum [no prelo].

LACERDA, Bruno Amaro; LOPES, Mônica Sette. Imagens da Justiça. São Paulo: LTr, 2010.

MARKUS, M. Lynne; ROBEY, Daniel. Information Technology and Organizational Change: causal structure in theory and research. Management Science, v. 34, n. 5, p. 583598, may 1988. Disponível em: <http://www.jstor.org/pss/2632080>. Acesso em: julho de 2011.

MAYOS, Gonçal. G. W. F. Hegel: vida, pensamento e obra. Trad. Catarina Mourão. Barcelona: Planeta De Agostini, 2008.

MAYOS, Gonçal. Genealogia i crítica del pensament únic. In: AAVV. Globalització; Pensament únic. Barcelona: Liceu Joan Maragall, La Busca Edicions, 2000. p. 17-40.

MAYOS, Gonçal; BREY, Antoni (Org.). La Sociedad de la Ignorancia. 2. ed. Barcelona: Península, 2011.

PALIWALA, Abdul. Free Culture, Global Commons and Social Justice in Information Technology Diffusion. Journal of Information, Law \& Technology (JILT), Coventry, University of Warwick, 2006.2 Disponível em: <http://www2.warwick.ac.uk/fac/soc/law/elj/jilt/2006_1/paliwala>. Acesso em: setembro de 2011.

PALIWALA, Abdul. Legal Regulation and uneven Global Digital Diffusion. Disponível em: <http:// www.bakercyberlawcentre.org/2004/talks/LTT_paliwala_digivide3.rtf>. Acesso em: julho de 2011.

PICARDO JOAO, Oscar Carlos. Pedagogía Informacional: Enseñar a aprender en la sociedad del conocimiento. Edutec, Revista Electrónica de Tecnología Educativa, Palma de Mallorca, Universitat de les Illes Balears, n. 15, mayo 2002. Disponível em: <http://edutec.rediris.es/Revelec2/revelec15/picardo.pdf >. Acesso em: julho de 2011.

REALE, Miguel. Nova Fase do Direito Moderno. 2. ed. São Paulo: Saraiva, 1998.

SARTORI, Giovanni. Homo Videns: televisão e pós-pensamento. Trad. Simonetta Neto. Lisboa: Terramar, 2000.

UNGER, Roberto Mangabeira. O que a Esquerda deve propor. Trad. Antonio Risério Leite Filho. Rio de Janeiro: Civilização Brasileira, 2008.

Web:

$\underline{\text { www.alcoberro.info }}$

www.klera.eu 
www.lagrandeconfusion.com

www.macrofilosofia.eu.

www.nicholasgcarr.com

www.sarasuati.com

www.ub.edu/histofilosofia/gmayos/0index.htm 